\title{
Epibrassinolide Promotes the Apoptotic Potential of Gemcitabine in Pancreatic Cancer Cells ${ }^{+}$
}

\author{
Fadina Kuryayeva, Elif Damla Arisan, Ajda Coker Gurkan and Pınar Obakan Yerlikaya * \\ Dept. of Molecular Biology and Genetics, Istanbul Kultur University, Atakoy Campus, 34156 Istanbul, \\ Turkey; fedinekuryayeva@gmail.com (F.K.); d.arisan@iku.edu.tr (E.D.A.); a.coker@iku.edu.tr (A.C.G.) \\ * Correspondence: p.obakan@iku.edu.tr; Tel.: +90-212-498-4567 \\ + Presented at the 3rd International conference on Natural Products for Cancer Prevention and Therapy, \\ Kayseri, Turkey, 18-20 December 2019.
}

Published: 25 December 2019

\begin{abstract}
Pancreatic cancer is a lethal disease for which the incidence and mortality rates are close. Patients with advanced stage have median survival of three months. Gemcitabine (GEM), the anticancer analog of deoxycytidine, has been considered standard care of pancreatic cancer. However, disease progression usually occurs. Despite the effort for better treatment options, phase trials fail due to severe side effects. Epibrassinolid (EBR) is a member of brassinnosteroids with similar chemical structure to steroid hormones. Our group showed that EBR induces apoptosis via endoplasmic reticulum stress induction both in in vitro and in vivo cancer models, without effecting non-cancerous cells or non-tumor bearing mouse. Our aim in this study is to evaluate whether EBR has the potential to increase the apoptotic effect of GEM in AsPc1 pancreatic cells. We showed by MTT assay that EBR has apoptotic efficiency in AsPc1 cells and it also increases the cell viability loss when combined with GEM. The combination of EBR $(30 \mu \mathrm{M})$ and GEM $(100 \mu \mathrm{M})$ further increases mitochondrial membrane potential loss and nuclear condensation. In addition, exposure of cells to EBR and GEM co-treatment induces subG1 apoptotic population showed by FACS flow analysis. Consequently, we suggest that the effect of GEM can be increased with EBR combination.
\end{abstract}

Keywords: pancreatic cancer; epibrassinolide; gemcitabine; apoptosis

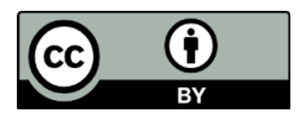

(C) 2019 by the authors. Licensee MDPI, Basel, Switzerland. This article is an open access article distributed under the terms and conditions of the Creative Commons Attribution (CC BY) license (http://creativecommons.org/licenses/by/4.0/). 